\title{
Modulator Upgrade of the KEK 2.5-GeV Linac
}

\author{
Tetsuo Shidara, Hiroyuki Honma, Shozo Anami, and Isamu Sato \\ KEK, National Laboratory for High Fnergy Physics \\ Oho, Tsukuba, Ibaraki, 305 Japan
}

\begin{abstract}
There is a plan to upgrade the energy of the KEK $2.5-\mathrm{GeV}$ linac to $8.5 \mathrm{GeV}$ relevant to the B-factory project. The increase from the present $2.5 \mathrm{GeV}$ requires reinforcing the cxisting microwave source. In order 10 realize this reinforcement with a limited budget, the upgraded modulator was designed so as to utilize those components of the old modulator as much as possible, cxpect for a necessary change in the main line components. This article describes the upgraded modulator specifications and its performance tests.
\end{abstract}

\section{INTRODUCTION}

Reinforcement of the KEK $2.5-\mathrm{GeV}$ linac from the present 2.5 to $8.5 \mathrm{GeV}$ is presently under consideration as a future project relevant to the KEK B-factory [1]. This energy upgrade necessitates replacing the existing 30-MW klystrons with new units [2], together with a certain microwave power multiplying scheme, such as a traveling-wave resonant ring or a SLED (SLAC energy doubler) [3]. Although the details concerning this energy upgrade have not yet been decided, we have started to modify one of the existing modulators at the klystron gallery (No. 4-6) in order to confirm the feasibility and long-term stability of this modification.

\section{MODULATOR SPECIFICATIONS}

There are two limitations concerning our modulator upgrade: the maximum available space at the klystron gallery and the budget for the modulator modification. Taking these limitations into account, the average power of the upgraded modulator was designed so as to be twice that of the existing modulator. This amount of reinforcement is the limit for us to utilize those components of the existing modulator as much as possible. The specifications of the original $|4|$ and two types of modified modulators (SLED and a traveling-wave resonant ring, respectively) are shown in Table 1 . A simplified diagram of the upgraded modulator is also shown in Figure 1. The rectifier transformer and charging transformer assemblies are water cooled in order to maintain the present volume. The inductance of the charging transformer was reduced to half that of the original modulator in order to realize the same charging time $(10 \mathrm{msec}$ ). A new pulse-forming network (PFN) which reuses the existing capacitors is being fabricated with two identical networks in parallel. This scheme lessens the effect of any residual inductance of the PFN capacitors, since the characteristic impedance of each network is twice that of the modulator.

Table 1

Comparison of the original and modified modulator specifications

\begin{tabular}{|c|c|c|c|}
\hline & Original & Modified (SLED) & Modilicd (recirculation) \\
\hline Maximum peak power (MW) & 84 & 117 & 153 \\
\hline Maximum average power $(\mathrm{kW})$ & 14.7 & 30 & 30 \\
\hline Transformer step-up ratio & $1: 12$ & $1: 13.5$ & $1: 15$ \\
\hline Output pulse voltage $(\mathrm{kV})$ & 23.5 & 23.5 & 23.5 \\
\hline Output pulse current (A) & 3600 & 5000 & 6530 \\
\hline PFN impedance $(\Omega)$ & 6.0 & 4.7 & 3.6 \\
\hline PFN total capacitance $(\mu \mathrm{F})$ & 0.3 & 0.6 & 0.6 \\
\hline Pulse width $(\mu s)$ & 3.5 & 5.6 & 4.3 \\
\hline Rise time $(\mu s)$ & 0.7 & 0.8 & 0.8 \\
\hline Fall time $(\mu s)$ & 1.2 & 1.3 & 1.5 \\
\hline Pulse repetition rate (pps) & 50 & 50 & 50 \\
\hline $\begin{array}{l}\text { Maximum pulse height } \\
\text { deviation from flatness }(\%)\end{array}$ & 0.3 (peak to peak) & 0.3 & 0.3 \\
\hline $\begin{array}{l}\text { Maximum pulse amplitude } \\
\text { drift (\%hour) }\end{array}$ & 0.3 & 0.3 & 0.3 \\
\hline Thyratron anode voltage $(\mathrm{kV})$ & 47 & 47 & 47 \\
\hline
\end{tabular}




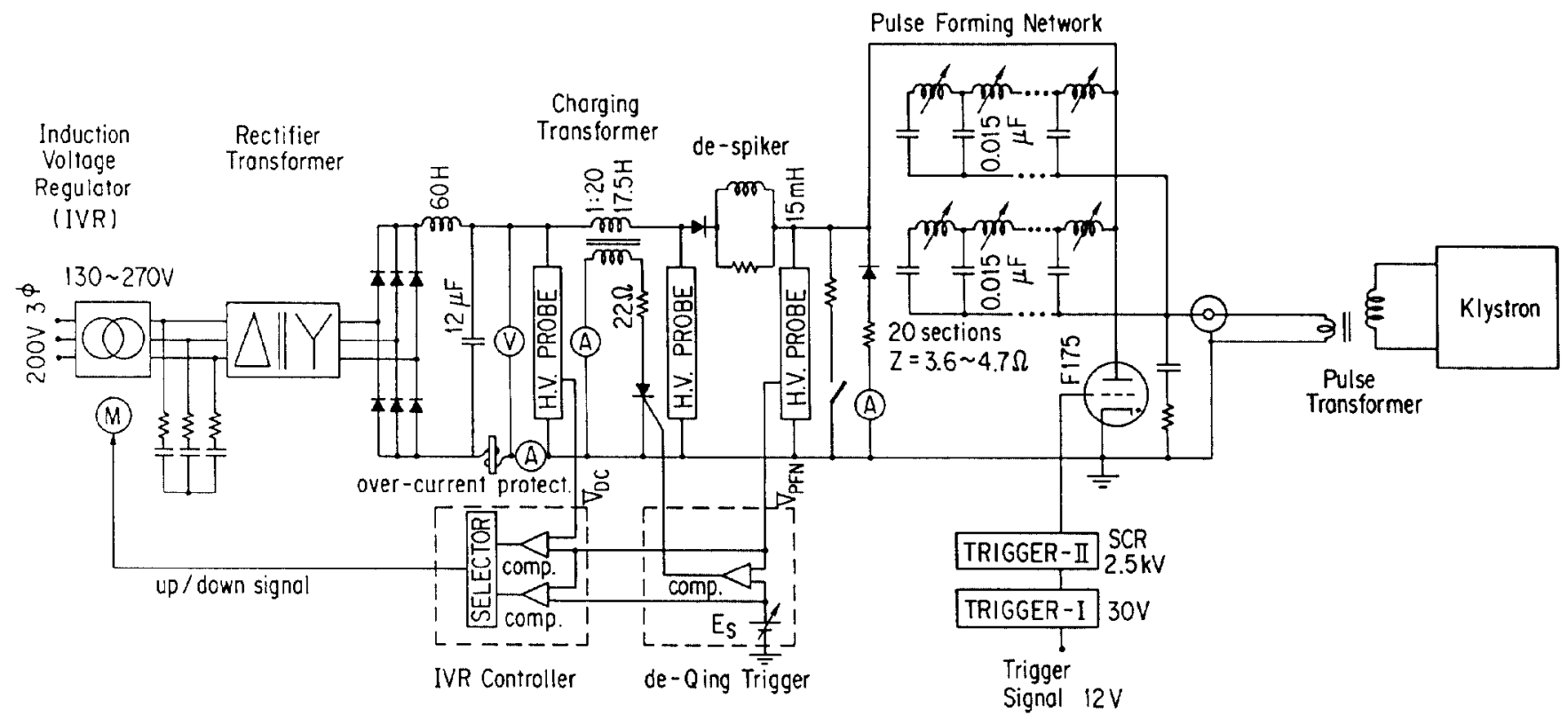

Figure 1. Simplified diagram of the upgraded klystron modulator.

\section{PERFORMANCE TESTS}

The No. 4-6 klystron modulator was reinforced in order to confirm the above-mentioned modification (see Figure 2).

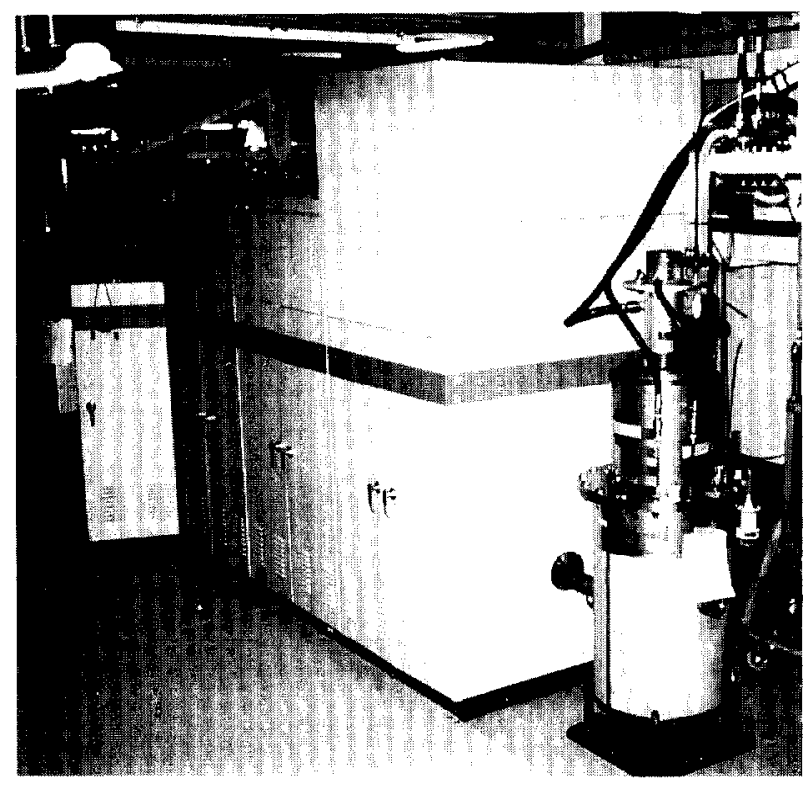

Figure 2. Modified klystron modulator in the klystron gallery.
Figure 3 shows the output pulse voltage (peak $-260 \mathrm{kV}$ ) and power output (peak $\sim 32 \mathrm{MW}$ ) waveforms. As an expanded trace of the pulse top shows in Figure 4, the pulse top was flat within $0.3 \%$ after adjusting the PFN inductances. The short-term pulse voltage stability was satisfactory and was less than $0.1 \%$.

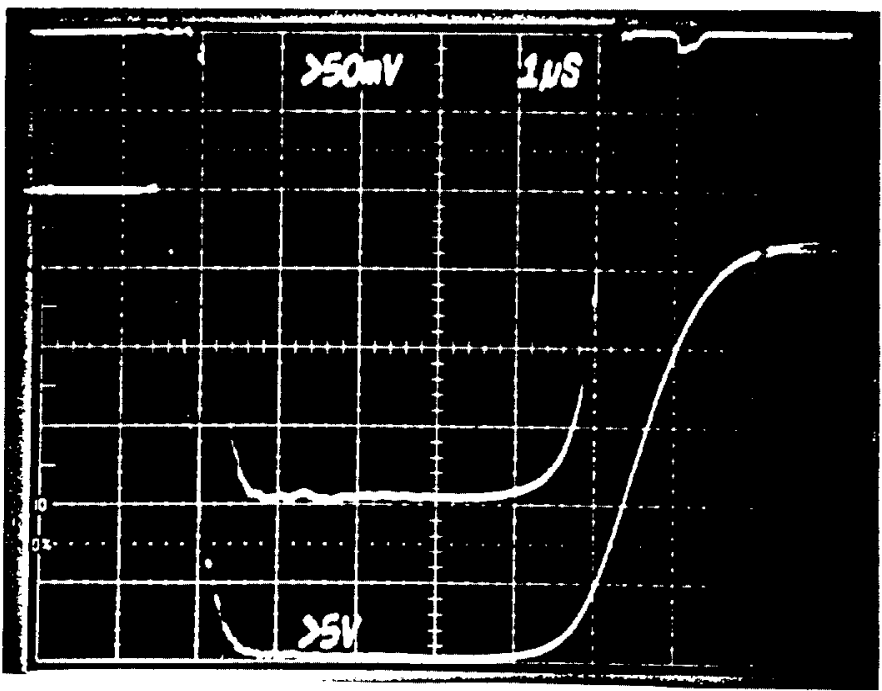

Figure 3. Power output (upper: peak $\sim 32 \mathrm{MW}$, hor. $1 \mu \mathrm{s} / \mathrm{div}$.) and output pulse voltage waveforms (lower: peak $\sim 260 \mathrm{kV}$ ). 


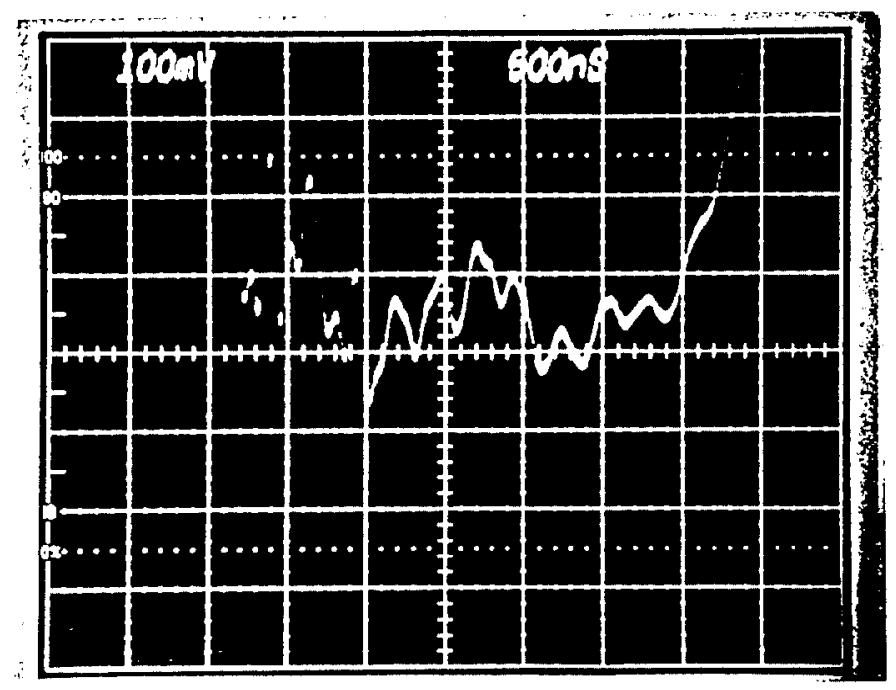

Figure 4. Expanded pulse top trace of the output pulse voltage (peak $-260 \mathrm{kV}$ ) at the klystron (vert. $0.2 \% /$ div., hor. $500 \mathrm{~ns} / \mathrm{div}$.).

\section{PRESENT STATUS AND FUTURE WORK}

After completing the modification in October, 1992, the No. 4-6 klystron modulator has been successfully operated for about 3000 hours for the use of practical tests utilizing a SLED-type cavity [5]. We are therefore planning to modify another eight klystron modulators in the gallery during FY1993 as the first step to reinforce the KEK injector linac relevant to the KEK B-factory project.

\section{REFERENCES}

[1] B Physics Task Force, "Progress report on physics and detector at KEK asymmetric B factory," KEK report 92-3 (1992).

A. Enomoto, et al., "Linac upgrade plan for the KEK Bfactory," these procecdings.

[2] S. Anami, et al., "The rf system of the Photon Factory injector linac," Proc. 1981 Linear Accelerator Conference, pp. 177-179.

S. Fukuda, et al., "Upgrade of an RF source of the KEK linac for B factory project," these proceedings.

[3] Z. D. Farkas, et al., "Recent progress on SLED, the SLAC energy doubler," IEEE Trans. Nurl. Sci NS22, No. 31299 (1975).

[4] T. Shidara, et al., "Klystron modulator for the KEK 2.5 GeV linac," Nucl. Instr. Meth. A279, 423 (1989).

[5] H. Matsumoto, et al., "High power test of a SLED system with dual side wall coupling irises for linear colliders," to be published in Nucl. Instr. Meth.: KEK preprint 92-179 Jan. (1993). 